\title{
Episodic-like memory in pigeons
}

\author{
THOMAS R. ZENTALL, TRICIA S. CLEMENT, RAMESH S. BHATT, and JESSICA ALLEN \\ University of Kentucky, Lexington, Kentucky
}

\begin{abstract}
It has been proposed that memory for personal experiences (episodic memory, rather than semantic memory) relies on the conscious review of past experience and thus is unique to humans. In an attempt to demonstrate episodic-like memory in animals, we first trained pigeons to respond to the (nonverbal) question "Did you just peck or did you just refrain from pecking?" by training them on a symbolic matching task with differential responding required to the two line-orientation samples and reinforcing the choice of a red comparison if they had pecked and the choice of a green comparison if they had not pecked. Then, in Experiment 1, after providing the conditions for (but not requiring) the pigeons to peck at one new stimulus (a yellow hue) but not at another (a blue hue), we tested them with the new hue stimuli and the red and green comparisons. In Experiment 2, we tested the pigeons with novel stimuli (a circle, which they spontaneously pecked, and a dark response key, which they did not peck) and the red and green comparisons. In both experiments, pigeons chose the comparison appropriate to the response made to the test stimulus. Thus, the pigeons demonstrated that they could remember specific details about their past experiences, a result consistent with the notion that they have the capacity for forming episodic-like memories.
\end{abstract}

Current views of human memory divide it according to the nature of what is remembered. For example, a distinction has been made between "knowing how to" (e.g., knowing how to ride a bicycle), often referred to as procedural memory, and "knowing what" (e.g., knowing what is the capital of California), often referred to as semantic memory. Most research on memory in animals viewed it as semantic in nature - that is, the learning of facts or rules. In Pavlovian conditioning, an animal learns, for example, that a particular stimulus is always followed by food, and in instrumental conditioning, for example, that food can always be found at the end of the runway. Such learning can be thought of as learning about the predictive value of a stimulus or behavior (Rescorla \& Wagner, 1972) or as the development of expectancies (Tolman, 1932).

A distinction has also been made between semantic memory and the ability to remember personal experiences, often referred to as episodic memory. According to Tulving (1985), episodic memory may distinguish humans from other animals. Tulving has referred to episodic memory as autonoetic (self-knowledge) because it requires consciousness (and perhaps also imagery). It is accepted that humans have episodic memory because as individuals we are personally conscious of the process of retrieving events from the past, but it is not so easy to study episodic memory in others. In fact, the best evidence for a distinctive

This research was supported by National Institute of Mental Health Grant MH-59194. Correspondence concerning this article should be sent to T. R. Zentall, Department of Psychology, University of Kentucky, Lexington, KY 40506-0044 (email: zentall@ pop.uky.edu). memory system for personal experiences in humans comes from research with brain-injured individuals who have lost the ability to remember those experiences (Vargha-Khadem et al., 1997). If consciousness is necessary for the demonstration of episodic memory, it may not be possible to demonstrate such a capacity in animals, because, in the absence of a well developed language system, it is not clear what would constitute evidence of consciousness. For this reason, we will use the term episodic-like memory when referring to analogous memory processes in animals.

Although consciousness cannot be demonstrated in animals, it may be possible to demonstrate that animals are capable of memory that has many of the characteristics of episodic memory. Tulving (1972) has proposed that a person who has access to episodic memory should be able to identify a past event in terms of what happened, where it happened, and when it happened. Unfortunately, this is neither sufficient nor necessary for defining episodic memory. First, many vivid episodes cannot be accurately placed in time. One may have a vivid memory for what happened at one's last visit to the dentist but be unable to remember the day or even the month of the event. In fact, we often use semantic memory as an aid in placing episodic events in time (e.g., "It must have been on a Monday because that is the only day that I have time to go to the dentist"). Second, merely knowing what has happened, as well as where and when it took place, is not sufficient evidence for one to conclude that such a memory is episodic. One can remember that the Declaration of Independence was signed on July 4th 1776 in Philadelphia but one would not claim that this memory is episodic. And even events that have been experienced may be remembered purely in se- 
mantic terms (e.g., I know that I watched the Boston Pops play a medley of patriotic tunes last July 4th, but I may not remember it at all).

Because it is impossible to ask a nonverbal organism to verbally recall a specific past experience, researchers have used indirect methods to examine this kind of memory in nonverbal organisms. For instance, researchers have examined episodic-like memory in human infants by requiring them to perform a task on the basis of a single prior episode in the absence of specific practice/training (Barr, Dowden, \& Hayne, 1996; Bauer, 1995; Mandler, 1990; Meltzoff, 1990, 1995; Rovee-Collier, 1997). The absence of training is thought to require the infants to retrieve specific episodic aspects of their experience. For instance, Meltzoff (1990) argued that the fact that infants imitate novel acts that they have previously witnessed even in the absence of any training/practice to do so must mean that they are able to retrieve episodic details about those acts. In other words, the infants' performance must involve some kind of mental "traveling back" to the experience of watching the performance of a novel act and the retrieval of specific details about this event. Thus, the absence of explicit training means that one should not expect that memory for the episode will be assessed.

To see more clearly how training may lead to a reliance on semantic or associative memory, rather than episodic memory, imagine the following scenario: We see a friend in the morning and ask him (unexpectedly) what he had for dinner last night. After a few seconds of reflection (presumably to search for the episode) he says, "Spaghetti." Imagine now that we ask him the same question every morning. Now, at dinner time, while eating chicken, he may say to himself, "When I am asked tomorrow what I had for dinner, I will say 'chicken."” The next day when asked the question he says to himself, "I don't have to think back about what I had for dinner because I know to say 'chicken."' This would be an example of semantic or associative memory rather than episodic memory, and it could be the basis for performance of any task with repeated trials. It is for this reason that accurate performance on a delayed conditional discrimination in which, say, an initial vertical-line stimulus is a cue to choose the red comparison (rather than the green one) whereas an initial horizontalline stimulus is a cue to choose the green comparison (rather than the red one) cannot be taken as evidence for episodic memory. Any task in which training involves what could be described as the acquisition of a set of rules cannot preclude semantic-like knowledge of the kind "if vertical then red, if horizontal then green." This is true even when the sample requires memory for "what," "where," and "when" information, such as that reported by Clayton and Dickinson (1999) and by Shimp (1976).

Clayton and Dickinson (1999) trained scrub jays to cache, in distinctive locations (where) for later retrieval, more preferred wax worms or less preferred peanuts (what). Because the more preferred wax worms went bad within a couple of days, time since caching (when) was manip- ulated as well. The jays learned to choose the wax worm if the time to recovery was relatively short and to choose the peanut if the time to recovery was relatively long. The fact that the jays had many experiences with the "rules" of the task makes it difficult to conclude that they were showing episodic memory (e.g., if a wax worm was cached on the left recently, choose left; if a wax worm was cached on the left a long time ago, choose right). To qualify as an example of episodic memory, the test must be unexpected, just as it was the first time we asked our friend what he had for dinner last night. If it is expected, we cannot rule out semantic memory as an account. It should be noted, of course, that not every unexpected test of memory with accurate performance is an example of episodic memory. An unexpected test provides necessary evidence, but it is not sufficient.

Unlike in humans, the problem with asking an animal an unexpected question is that we have no language (quite literally a form of semantic knowledge) with which to ask. Language can be thought of as a set of commonly held rules that, among other things, allow questions to be asked (and answered). A similar, but greatly simplified, set of rules must be acquired by the animal prior to the assessment of episodic memory to ensure that the task "instructions" are understood (Zentall, 1997). The form of the instructions or rules depends on the nature of the episodic memory assessed. We propose that asking an animal about its own recent behavior may qualify as an episode to be remembered. But, to ask an animal about its own behavior, we must first train the animal to respond in a particular way when one behavior has occurred and to respond in a different way when a different behavior has occurred. In pigeons, such training might involve the acquisition of two rules: First, in the presence of a vertical line, the pigeons must learn to peck, and then, the choice of a red light (rather than a green light) will result in reinforcement. Second, in the presence of a horizontal line, the pigeon must learn to refrain from pecking, and then the choice of a green light (rather than a red light) will result in reinforcement (Urcuioli \& Honig, 1980; see also Shimp, 1982). The rules of this task can be described as, "If pecking has just occurred, choose red; if pecking has not just occurred, choose green." Thus, one can consider the choice of the red or green comparison stimulus as analogous to answering the question, "Did you just peck or did you just refrain from pecking?" Presentation of the vertical or horizontal line should provide a means of evaluating the animal's semantic knowledge. Presentation of a line sample should create an "expectation" that if an appropriate response is made (pecking or the absence of pecking), a red/ green choice will be provided and choice of the correct hue will yield a reward.

Next, one should provide the pigeon with an experience of either pecking or not pecking under conditions where there is no expectation of being asked about its recent behavior. This would be analogous to a human experiencing an event for which there is no prior expectation of having 
to remember it (e.g., being asked to report what was eaten last night). On test trials, one could then present the one or the other target event followed by a red/green choice, thereby asking the pigeon whether it can remember that recent behavior. For example, there is good evidence that if a localized visual stimulus (e.g., a yellow hue projected on to a response key) is followed by the presentation food, pigeons will spontaneously peck at the hue, even though pecking has no programmed consequence (Brown \& Jenkins, 1968). Furthermore, if a different localized stimulus (e.g., a blue hue projected on to the response key) is not followed by food, generally, pigeons will not peck (discriminated autoshaping; Wilkie \& Ramer, 1974). Such training should allow for the experimental control of two behaviors (pecking and the absence of pecking) without providing the expectation of a red/green choice. A test of episodic memory would consist of the presentation of the yellow hue or the blue hue followed by the (unexpected) red/green choice (i.e., asking the question, "Did you just peck?" or "Did you just refrain from pecking?" or more generally, "What was the behavior that you most recently engaged in?"). Given differential responding to the yellow and blue hues, episodic memory would be suggested by choice of the red hue following presentation of the yellow hue (and pecking), and by choice of the green hue following presentation of the blue hue (and the absence of pecking).

\section{EXPERIMENT 1}

\section{Method}

\section{Subjects}

The subjects were 8 White Carneaux pigeons, purchased as retired breeders (5-8 years old) from the Palmetto Pigeon Plant (Sumter, SC). The pigeons were maintained at $80 \%$ of their free-feeding body weights throughout the experiment and were caged individually with grit and water continually available in the home cage. The colony room in which the pigeons were housed was maintained on a 12:12-h light:dark cycle. All pigeons had previously served in an unrelated study involving simple simultaneous discriminations.

\section{Apparatus}

The experiment was conducted in a BRS/LVE (Laurel, MD) sound-attenuating pigeon test chamber. The test chamber measured $30 \mathrm{~cm}$ (from the response panel to the back wall) $\times 36 \mathrm{~cm}$ (across the response panel) $\times 36 \mathrm{~cm}$ (high). Three rectangular response keys $(2.5 \mathrm{~cm}$ high $\times 3 \mathrm{~cm}$ wide), were separated from each other by $1 \mathrm{~cm}$ and were aligned horizontally on the response panel. Mounted behind each response key was a 12-stimulus in-line projector (Industrial Electronics Engineering, Series 10, Van Nuys, CA, with No. 1820 G. E. lamps) that projected a yellow hue (Kodak Wratten Filter No. 9), a blue hue (Kodak Wratten Filter No. 38), a white circle shape (an annulus with 16-mm outside diameter and 13-mm inside diameter), three white vertical lines $(2.4 \mathrm{~cm}$ long, $0.3 \mathrm{~cm}$ wide, and $0.3 \mathrm{~cm}$ apart), and three white horizontal lines (the shape and lines on a black background) on the center response key. Red and green hues (Kodak Wratten filters, Nos. 26 and 60, respectively) were projected on the left and right response keys. A houselight located at the center of the chamber ceiling provided general illumination during intertrial intervals. A rear-mounted grain feeder was centered horizontally on the response panel midway between the pecking keys and the floor of the chamber.
When operated, the feeder was lit and accessible through a $5.0 \times 5.5$ $\mathrm{cm}$ aperture in the response panel. Reinforcement consisted of 1.5sec access to Purina Pro Grains. White noise and an exhaust fan mounted on the outside of the chamber masked extraneous noise. The experiment was controlled by a microcomputer located in an adjacent room.

\section{Procedure}

Phase 1. Phase 1 consisted of symbolic matching-to-sample training with differential responding required to the samples. Each trial began with the onset of the sample (vertical or horizontal lines on the center key). For all pigeons, a fixed interval (FI) 4-sec schedule was in effect in the presence of the vertical-line stimulus (the first peck after $4 \mathrm{sec}$ darkened the vertical-line stimulus), whereas a differential reinforcement of other behavior (DRO) 4-sec schedule was in effect in the presence of the horizontal-line stimulus (the offset of the horizontal-line stimulus required that the pigeon refrain from pecking for $4 \mathrm{sec}$ ).

Immediately following the offset of the sample, red and green comparisons were presented on the side keys (randomly with respect to location, with the restriction that a particular hue could not occur on the same side key for more than three consecutive trials). For half of the pigeons, a single peck to red following a vertical sample and a single peck to green following a horizontal sample resulted in reinforcement and a 10-sec intertrial interval. Incorrect choices resulted in the 10-sec intertrial interval alone. For the remaining pigeons, the comparisons associated with correct responding to the samples were reversed.

All pigeons received 96 trials per session, with equal numbers of vertical and horizontal trials per session. Sessions were conducted 6 days a week. For each pigeon, a discrimination ratio was calculated for the vertical and the horizontal trials by dividing pecks to the FI stimulus by pecks to both the FI and DRO stimuli. Criterion was met for each pigeon in Phase 1 when the discrimination ratio for vertical and horizontal trials was at least .90 for two consecutive sessions and the correct comparison for each sample was chosen on at least $90 \%$ of those trials for two consecutive sessions. Following criterion performance, each pigeon received five sessions of overtraining to ensure stability of performance.

Phase 2. Phase 2 consisted of differential autoshaping. Each trial began with the 4-sec presentation of either a yellow or a blue center key light. All presentations of yellow were followed by reinforcement (response noncontingent) and the intertrial interval. All presentations of blue were followed by the intertrial interval alone. All pigeons received 96 trials per session, randomly determined, with the constraint that there were equal numbers of yellow and blue trials per session. Additionally, to ensure that pigeons maintained performance of the Phase 1 task, all birds were given 24 "refresher trials" (12 vertical- and 12 horizontal-sample trials) following each session.

In differential autoshaping, although pecking is not required to the stimulus that is consistently followed by the presentation of food, it typically does occur, but it typically does not occur to the stimulus that is not followed by food. A discrimination ratio was calculated for the yellow- and blue-stimulus trials by dividing pecks to the yellow stimulus by pecks to both the yellow and the blue stimuli. Criterion was met for each pigeon in Phase 2 when, for two consecutive sessions, the following three conditions were met: (1) The discrimination ratio for yellow and blue trials was .90 or higher for two consecutive sessions, (2) the discrimination ratio for vertical- and horizontal-sample refresher trials was at least .80 for two consecutive sessions, (3) the correct comparison for each sample was chosen on at least $80 \%$ of those trials. Following criterion performance, the pigeons received five sessions of overtraining.

Test. On test trials, yellow and blue hues were presented for $4 \mathrm{sec}$, followed (for the first time) by the presentation of red and green comparison stimuli. For half of the pigeons (the consistent group), choice 
of the comparison that was correct following presentation of the vertical (FI) stimulus in Phase 1 was correct following the yellow stimulus, whereas choice of the comparison that was correct following presentation of the horizontal (DRO) stimulus in Phase 1 was correct following the blue stimulus. For the remaining pigeons (the inconsistent group), those contingencies were reversed. The test consisted of a single 96-trial test session with equal numbers of trials initiated by the yellow and blue stimuli. The design of Experiment 1 appears in Table 1.

\section{Results}

\section{Phases 1 and 2}

Pigeons acquired to criterion the Phase 1 symbolic matching task with differential sample responding in a mean of 9.3 sessions. They acquired the differential autoshaping task to criterion in a mean of 5.2 sessions.

\section{Test}

Accuracy on test trials was above chance $(71.4 \%)$ for the consistent group, and it was below chance $(39.6 \%)$ for the inconsistent group. In all statistical analyses, the .05 level of significance was adopted. A one-way analysis of variance performed on the transfer data indicated that the two groups differed significantly $[F(1,6)=36.36]$.

To assess the pigeons' initial reaction to the test trials, a further analysis was conducted on data from the first four test trials for each pigeon. (The first four test trials for each pigeon represented one trial each of the four possible test trial types.) Because only one trial of each trial type was considered and thus the consequences of reinforcement on one trial should have had little effect on the other trials, for purposes of this analysis the data were scored relative to the assumed correspondence between sample responding and comparison choice (i.e., independently of the actual conditions of reinforcement on test trials). The analysis indicated that the pigeons chose comparisons in accordance with sample pecking on a significant percentage $(68.8 \%)$ of those trials $[F(1,7)=21.00]$.

\section{Discussion}

The purpose of Phase 1 was to establish a means of asking the pigeon whether it had just pecked or not. We reasoned that by the end of Phase 1 training, presentation of the red/green choice should have served this role. The pur- pose of Phase 2 was to present the pigeons with a stimulus that we had reason to believe they would peck and another that we had reason to believe they would refrain from pecking. But to maintain the analogy to episodic memory in humans, there should be no requirement that they do so, and there should be no test "asking" them what they had done. On test trials, we presented the pigeons with a yellow stimulus and with a blue stimulus and asked them (for the first time with those stimuli) whether they had just pecked or not. These pigeons showed a reliable ability to tell us what they had just done.

However, although pecking to the yellow stimulus was not required in Phase 2, one could argue that the pairing of that stimulus with reinforcement encouraged the pigeons to peck, and that encouraging them to peck produced a form of semantic or rule-based knowledge. Of course, the rules did not include the comparison stimuli. They merely involved the presence versus the absence of food. Nevertheless, in Experiment 2 we attempted to provide the pigeons with experiences more analogous to human episodic memories.

In Experiment 2, we asked whether, in the absence of Phase 2 training, (1) presentation of a novel stimulus on test trials might result in untrained pecking that in turn would lead to an appropriate "Yes, I pecked" response (i.e., choice of the red comparison stimulus), and (2) presentation of no stimulus on test trials (also a novel event), which should result in the absence of pecking, would lead to an appropriate "No, I did not peck" response (i.e., choice of the green comparison stimulus). In Experiment 2, to avoid extensive experience with the test conditions (i.e., to make the conditions more similar to the conditions associated with the assessment of episodic memory in humans), it was further decided to test the pigeons for only a small number of trials (one trial involving each trial type).

\section{EXPERIMENT 2}

\section{Method}

\section{Subjects and Apparatus}

The subjects and apparatus were the same as those in Experiment 1.

\section{Procedure}

Retraining. All pigeons were returned to the symbolic matching task with differential sample responding used in Phase 1 of Exper-

Table 1

Design of Experiment 1

\begin{tabular}{|c|c|c|c|}
\hline \multirow[t]{2}{*}{ Phase 1} & Samples & Required Response & Comparisons \\
\hline & $\begin{array}{l}\text { vertical lines } \\
\text { horizontal lines }\end{array}$ & $\begin{array}{l}\text { pecking } \\
\text { not pecking }\end{array}$ & $\begin{array}{l}\text { red*/green } \\
\text { red/green* }\end{array}$ \\
\hline \multirow[t]{2}{*}{ Phase 2} & Stimuli & $\underline{\text { Required Response }}$ & Outcome \\
\hline & $\begin{array}{l}\text { yellow } \\
\text { blue }\end{array}$ & $\begin{array}{l}\text { none } \\
\text { none }\end{array}$ & $\begin{array}{l}\text { food } \\
\text { no food }\end{array}$ \\
\hline \multirow[t]{2}{*}{ Test } & Stimuli & $\underline{\text { Required Response }}$ & Comparisons \\
\hline & $\begin{array}{l}\text { yellow } \\
\text { blue }\end{array}$ & $\begin{array}{l}\text { none } \\
\text { none }\end{array}$ & $\begin{array}{l}\text { red/green } \\
\mathrm{red} / \text { green }\end{array}$ \\
\hline
\end{tabular}

Note-In Phase 1, the asterisk indicates the correct comparison response. 
iment 1 for sufficient sessions to attain the criterion of two sessions at $90 \%$ correct or better and a discrimination ratio involving responding to the vertical and horizontal samples of .90 or better.

Test. Each trial began with a 4-sec presentation of either a circle stimulus on the center key or a 4-sec presentation of no stimulus (i.e., a dark response key). For half of the pigeons originally tested in the consistent condition and for half of the pigeons originally tested in the inconsistent condition, the comparison associated with responding to the sample was reinforced following the presentation of the circle stimulus on the center key and the comparison associated with not responding to the sample was reinforced following the presentation of the dark key (the novel consistent group). For the remaining pigeons (half originally tested in the consistent condition and half originally tested in the inconsistent condition), the comparison associated with not responding to the sample was reinforced following the circle stimulus and the comparison associated with responding to the sample was reinforced following the presentation of the dark key (the novel inconsistent group). All pigeons received two trials in which the novel circle served as the sample (one test trial in which the red comparison appeared on the left response key and one test trial in which the red comparison appeared on the right response key) and two trials in which there was no sample (i.e., the response key was dark for $4 \mathrm{sec}$ ).

\section{Results}

Retraining on the symbolic matching task with differential sample responding to criterion took a mean of 5.2 sessions. The transfer data indicated that the pigeons did indeed peck the novel circle $(M=3.32$ pecks/trial) and that they generally refrained from pecking the dark response key $(M=0.10$ pecks/trial $)$. In addition, the pigeons tended to choose the red comparison on trials involving the novel circle as the sample and they tended to choose the green comparison on trials involving the dark response key as the sample. Over the four test trials, they chose the comparison hue according to whether they had pecked the sample or had refrained from pecking the sample $71.9 \%$ of the time. This percentage was significantly different from chance $(50 \%)[F(1,7)=14.91]$.

\section{Discussion}

In Experiment 2, when the pigeons were presented with novel test stimuli, a circle that they tended to peck and a dark response key that they tended to refrain from pecking, and they were then "asked" what they had just done, they responded according to their most recent behavior, choosing red if they had just pecked and green if they had just refrained from pecking. Given the fact that the circle and the dark-response-key stimuli were novel and in test each stimulus had been presented only twice, the data suggest that the pigeons were retrieving the memory of those episodes in the absence of the expectation that they would be asked to retrieve those memories, and thus in the absence of a semantic memory associated with those stimuli. Whether these data qualify as episodic memory of the kind referred to by Tulving (1985) as autonoetic is difficult to say, because it may not be possible to demonstrate in animals the kind of dissociation used as evidence for such memory in humans. However, in other respects, the present results offer at least suggestive evidence for the pigeons' ability to retrieve knowledge of recent experiences under conditions in which the pigeons should not anticipate a request to retrieve such knowledge.

A similar but more sophisticated approach to episodic memory in animals has been taken recently by Mercado, Murray, Uyeyama, Pack, and Herman (1998). They used dolphins that had been extensively trained to perform a number of complex responses when given an arm-gesture command. Embedded within commands to perform certain specific responses, they were trained on command to repeat the response that they had most recently made. They were also trained with an arm gesture that required them to "do something/anything that they had not recently done" (i.e., a relatively novel response). Finally, they were successfully tested with the "do something not recently done" gesture followed by the "repeat the most recent response" gesture. Thus, the dolphin must have been using its own behavior as the basis for the current response, rather than using the gesture from the previous trial as the basis for the current response, because the prior gesture indicated only that the dolphin perform a relatively novel response.

Other research also may reflect evidence for episodic memory in animals. In a design similar to that of the Experiment 1 of the present research, Urcuioli and Honig (1980, Experiment 3) trained pigeons to respond differentially to two samples in a matching task. They then trained the pigeons, off baseline, to respond differentially to two stimuli. The transfer that they found when they then replaced the original samples with the stimuli trained off baseline suggests that the pigeons may have been consulting episodic memory. However, the present experiments provide more definitive evidence for episodic-like memory because in Experiment 1 of the present research, the pigeons were not explicitly reinforced for differential responding. Furthermore, in Experiment 2 of the present research, transfer was found with novel stimuli (i.e., stimuli that had not been experienced previously).

The present data, together with those reported by Mercado et al. (1998), provide convergent evidence that processes similar to episodic memory occur in animals. Furthermore, the fact that these findings were obtained with pigeons, a species quite different from humans and dolphins, suggests that this form of memory may represent a general capacity in animals.

The results of the present research can also be viewed from a different perspective. If one were dealing with a nonverbal human, what evidence would one accept that such a person had episodic memory? In other words, is the verbal description of a past event necessary (or even sufficient) to demonstrate episodic memory? Although the approach used in the present research may not provide definitive evidence for the capacity for episodic memory in pigeons, it may help us to gain the perspective needed to better formulate questions about analogous human capacities. 


\section{REFERENCES}

Barr, R., Dowden, A., \& Hayne, H. (1996). Developmental changes in deferred imitation by 6- to 24-month-old infants. Infant Behavior \& Development, 19, 159-170.

BAUER, P. J. (1995). Recalling past events: From infancy to early childhood. Annals of Child Development, 11, 25-71.

Brown, P. L., \& Jenkins, H. M. (1968). Auto-shaping the pigeon's key peck. Journal of the Experimental Analysis of Behavior, 11, 1-8.

Clayton, N. S., \& Dickinson, A. (1999). Scrub jays (Aphelocoma coerulescens) remember the relative time of caching as well as the location and content of their caches. Journal of Comparative Psychology, 113, 403-416.

MANDLER, J. (1990). Recall of events by preverbal children. In A. Diamond (Ed.), The development and neural bases of higher cognitive functions (Annals of the New York Academy of Sciences: Vol. 608, pp. 485-516). New York: New York Academy of Sciences.

Meltzoff, A. N. (1990). Towards a developmental cognitive science. In A. Diamond (Ed.), The development and neural bases of higher cognitive functions (Annals of the New York Academy of Sciences: Vol. 608, pp. 1-37). New York: New York Academy of Sciences.

Meltzoff, A. N. (1995). What infant memory tells us about infantile amnesia: Long-term recall and deferred imitation. Journal of Experimental Child Psychology, 59, 497-515.

Mercado, E., III, Murray, S. O., Uyeyama, R. K., Pack, A. A., \& Herman, L. M. (1998). Memory for recent actions in the bottlenosed dolphin(Tursiops truncatus): Repetition of arbitrary behaviors using an abstract rule. Animal Learning \& Behavior, 26, 210-218.

Rescorla, R. A., \& WAgner, A. R, (1972). A theory of Pavlovian conditioning: Variations in the effectiveness of reinforcement and nonreinforcement. In A. H. Black \& W. F. Prokasy (Eds.), Classical conditioning II: Current research and theory (pp. 64-99). New York: Appleton-Century-Crofts.
Rovee-Collier, C. (1997). Dissociations in infant memory: Rethinking the development of implicit and explicit memory. Psychological Review, 104, 467-498.

Shimp, C. P. (1976). Short-term memory in the pigeon: Relative recency. Journal of the Experimental Analysis of Behavior, 25, 55-61.

SHIMP, C. P. (1982). On metaknowledge in the pigeon: An organism's knowledge about its own behavior. Animal Learning \& Behavior, 10, 358-364.

Tolman, E. C. (1932). Purposive behavior in animals and men. New York: Appleton-Century-Crofts.

Tulving, E. (1972). Episodic and semantic memory. In E. Tulving \& W. Donaldson (Eds.), Organization of memory (pp. 382-403). New York: Academic Press.

Tulving, E. (1985). How many memory systems are there? American Psychologist, 40, 385-398.

Urcuioli, P. J., \& Honig, W. K. (1980). Control of choice in conditional discriminations by sample-specif ic behaviors. Journal of Experimental Psychology: Animal Behavior Processes, 6, 251-277.

Vargha-Khadem, F., Gadian, D. G., Watkins, K. E., Connelly, A. Van Paesschen, W., \& Mishrin, M. (1997). Differential effects of early hippocampal pathology on episodic and semantic memory. Science, 277, 376-380.

WilkiE, D. M., \& RAMER, D. G. (1974). Errorless discrimination established by differential autoshaping. Journal of the Experimental Analysis of Behavior, 22, 333-340.

Zentall, T. R. (1997). Animal memory: The role of "instructions." Learning \& Motivation, 28, 280-308.

(Manuscript received July 10, 2000; revision accepted for publication February 2, 2001.) 